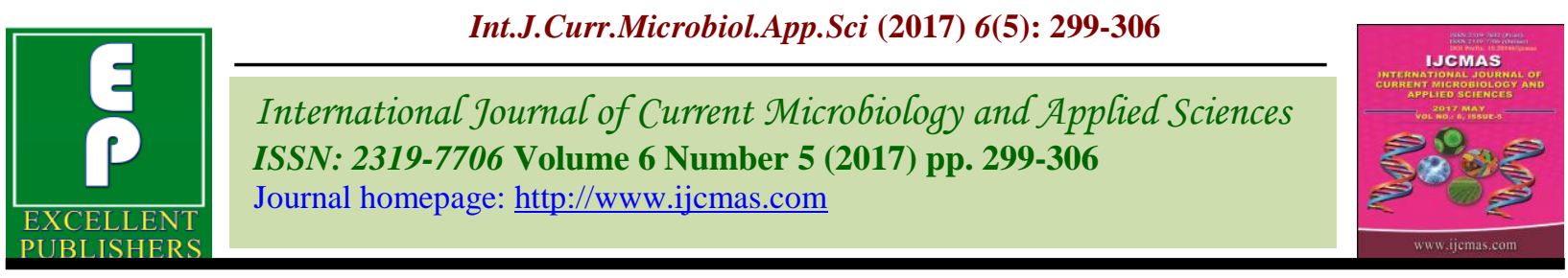

Original Research Article

https://doi.org/10.20546/ijcmas.2017.605.034

\title{
Forecast Verification Analysis of Rainfall for Southern Districts of Tamil Nadu, India
}

\author{
M. Joseph ${ }^{1}$, E. Murugan ${ }^{1}$ and M. Hemalatha ${ }^{2}$ \\ ${ }^{1}$ Agricultural Research Station, Kovilpatti - 628 501, India \\ ${ }^{2}$ Agricultural College and Research Institute, Killikulam, Tamil Nadu Agricultural University \\ Thoothukudi District, Tamil Nadu, India \\ *Corresponding author
}

\section{A B S T R A C T}

\section{Keywords}

Rainfall, Forecast verification, Southern district of Tamil Nadu.

\section{Article Info}

Accepted: 04 April 2017 Available Online: 10 May 2017
The weather forecast and actual weather data received from Indian Meteorological Department, Pune were compared to verify the accuracy of rainfall forecast for the year 2015- 16 at AMFU centre, Kovilpatti, Tamil Nadu. The forecast verification for rainfall verified by using the statistical tools of Forecast Accuracy, Critical Success Index, Heidke Skill Score and Hanssen and Kuipers Scores. The analysis of rainfall verification revealed that, the number of hits (predicted and observed as no rain - NN) was 47.0, $35.0 \& 44.0$, the occurrences of rain (YY) was 29.2, $43.2 \& 32.2$, the numbers of false alarms (YN) was 28. $17.2 \& 21.0$ and the number of misses (NY) were $6.6,8.8 \& 7.0$ over 104 forecast for Virudhunagar, Tirunelveli and Thoothukudi district, respectively. Forecast Accuracy (ACC) ranged from 0.7 to 0.8 and the highest accuracy of rainfall prediction was observed in Tirunelveli district followed by Virudhunagar and Thoothukudi. Similarly Critical Success Index (CSI) was recorded the values of $0.51,0.60$ and 0.50 for Virudhunagar, Tirunelveli and Thoothukudi district, respectively. Heidke Skill Score (HSS) was accounted as 0.50 for three districts. Among the five days of forecast, ACC for Virudhunagar registered the higher accuracy of rainfall prediction at day 1 and 3 (78 per cent) followed by day 5 (71 per cent). For Tirunelveli, day 1 recorded the higher accuracy (81 per cent) followed by day 4 (78 per cent). The higher accuracy of rainfall prediction of 78 per cent for day 1 and 77 per cent for day 3 were recorded at Thoothukudi district.

\section{Introduction}

The verification of forecast is important in order to find out its accuracy by comparing the predicted weather with the observed weather either qualitatively or quantitatively. In either case, it should give information about the nature of the forecast errors either by its strength or weaknesses of a forecast system. Verification of rainfall is very crucial as it is one of the important end products with more practical application to the user community.
As it is being very discontinuous parameters and the representativeness of the ground truth against which the verification is to be carried out mostly depends on the quality, density and the pre-processing of the observed data. Also the traditional point-to-point verification adopted for other continuous types of variables may not reveal the spatially coherent characteristics of the discontinuous parameter like rainfall and cloudiness. 
A weather element may be either a continuous or a categorical variable. Parameters like rainfall take discrete values like 0 (no rain) and 1 (rain) and hence is a categorical variable. On the other hand, parameters like wind speed, wind direction, temperature, dew point and the percentage of sky covered by cloud will always occur and hence are quasicontinuous variable.

\section{Materials and Methods}

Gramin Krishi Mausam Sewa (Agromet advisory service) is being implemented at ARS, Kovilpatti since 1996 by the India Meteorological Department (IMD). From IMD the weather forecast for Tirunelveli, Thoothukudi and Virudhunagar districts is received on every Tuesday and Friday for the next five days after value addition which is done at the Regional Meteorological Centre, Chennai.

The weather parameters forecasted are maximum temperature, minimum temperature, relative humidity of morning and afternoon, cloud cover, rainfall and wind speed and direction. Based on crop information and weather forecast received from the IMD, Pune, the agromet advisory bulletin is prepared for the next five days for the domain districts.

The bulletin contain advisories pertaining to selection of variety, sowing time, input management, in situ moisture conservation, plant protection measures and contingency plans on need basis.

Meteorologists have developed methods for forecast verification with a variety of purpose in mind for multitude of situations. Here, the term situation relates to consideration such as nature of meteorological variable
(Continuous, discrete, ordered/ unordered, bounded/ unbounded).

The standard approach is to record the frequencies with which the event was observed and forecasted in a two by- two tables, and then to quantify forecast quality with summary measures of the table. The frequency with which rare events are observed may be low, which increases sampling variation in such measures and creates uncertainty about forecast quality (Ferro Christopher, 2007).

The aim of the study to verify the forecast values of rainfall during monsoon with the recorded values with different types of statistical tools which are presented.

A weather element may be either a continuous or a categorical variable. Parameters like the rainfall take discrete values like 0 (no rain) and I (rain) and hence is a categorical variable.

On the other hand parameters like the wind speed, wind direction, temperature, dew point and the percentage of sky covered by cloud will always occur and hence are quasicontinuous variable.

\section{Verification methods- categorical or discrete variable}

Non-probabilities forecast of the categorical weather elements are verified by utilizing the contingency table approach, which can serve as the starting point for examination of the strengths and weakness of the forecast (Murphy and Winkler, 1987, Murphy et al., 1989 and Schafer, 1990). It gives information about the skill of the forecast as well as the type of errors that occur in the forecast. 


\begin{tabular}{c|l|l|l}
\multirow{2}{*}{ Observed } & \multirow{2}{*}{ No rain } & Nodicted & \\
\cline { 2 - 3 } & Z (NN) & F $(\mathrm{NY})$ \\
\cline { 2 - 4 } & Rain & $\mathrm{M}(\mathrm{YN})$ & $\mathrm{H}(\mathrm{YY})$
\end{tabular}

Where,

$\mathrm{Z}=$ No. of correct prediction of no rain (predicted or observed).

$\mathrm{F}=$ No. of false alarms (not predicted but observed)

$\mathrm{M}=$ No. of misses (predicted but not observed) and

$\mathrm{H}=$ No of Hits (predicted and observed)

\section{Forecast Accuracy (ACC) or Ratio Score} or Hit Score

number of forecasts. It varies from 0 to 1 with 1 indicating perfect forecast.

It is the ratio of correct forecast of the total

$$
\mathrm{ACC}=\frac{\text { Correct Forecast }}{\text { Total Forecast }}=\frac{\mathrm{H}+\mathrm{Z}}{\mathrm{N}}=\frac{\mathrm{YY}+\mathrm{NN}}{(\mathrm{YY}+\mathrm{NN}+\mathrm{YN}+\mathrm{NY})}
$$

Where $(\mathrm{N}=\mathrm{Z}+\mathrm{F}+\mathrm{M}+\mathrm{H})$

Critical Success Index or Threat Score defined as the ratio of the number of hits (CSI) (correct event forecast) to the number of events which occurred plus the number or

It is a measure of relative forecasting accuracy (e.g. rain or no rain). It varies from 0 false alarms (incorrect event forecasts) to 1 with 1 indicating perfect forecast and is (Schafer, 1990).

$$
\text { CSI }=\frac{\text { Correct Rain Forecast }}{\text { Rain Forecast + Observations }}=\frac{\mathrm{H}}{\mathrm{F}+\mathrm{M}+\mathrm{H}}
$$

\section{Heidke Skill Score (HSS)}

It accounts for all correct forecast (events and non- events) that would be made due to chance. It varies from -1 to 1 with 0 indicating no skill compared with random or chance forecast.

$$
\text { HSS }=\frac{\text { Correct Forecast }-(\text { Correct Forecasts })_{\text {random }}}{\mathrm{N}-(\text { Correct forecasts })_{\text {random }}}
$$


The number of correct forecasts expected for random chance is

$$
(\text { Correct forecasts })_{\text {random }}=\frac{(\mathrm{Z}+\mathrm{F})(\mathrm{Z}+\mathrm{M})+(\mathrm{M}+\mathrm{H})(\mathrm{F}+\mathrm{H})}{\mathrm{N}}
$$

\section{Results and Discussion}

The forecast thus verified with the actual weather data by adopting the standard method of forecast verification and the results are presented below.

\section{Forecast Accuracy (ACC) or ratio score or hit score}

The analysis of rainfall verification for the year April 2015- March 2016 revealed that, the number of hits (predicted and observed as no rain - NN) was 47.0 as well as the occurrences of rain (YY) was 29.2. But the numbers of false alarms (predicted but not observed (YN) was 28.1 and the number of misses (not predicted but observed (NY) were 6.6 over 104 forecast for Virudhunagar district. Similarly, the number of hits (NN 35.0), ( $\mathrm{YY}$ - 43.2) and the number of false alarms (YN - 17.2) and number of misses (NY - 8.8) were witnessed for Tirunelveli district. In case of Thoothukudi district, the number of hits (predicted and observed) as no rain $(\mathrm{NN})$ was 44.0 as well as occurrences of rain (YY) was 32.2. But the number of false alarms (predicted but not observed - YN) were 21.0 and the number of misses (not predicted but observed - NY) were 7.0 over 104 forecast received during the period 201516

ACC is the ratio of correct forecast to total number of forecast for rainfall events. It is worked out on Yes/ No basis for day 1to day 5 and the average of five days for
Virudhunagar, Tirunelveli and Thoothukudi district. The ratio score revealed that the accuracy score for Virudhunagar district ranged from 69 to 78 per cent with an average of 73 per cent. The highest accuracy of rainfall prediction was observed for day 1 and day 3 (78 per cent) followed by day 5 (71 per cent). Similarly for Tirunelveli district, the accuracy ranged from 71 to 81 per cent with an average score of 80 and the day 1 recorded the highest accuracy of rainfall prediction (81 per cent) followed by day 4 (78 per cent). For Thoothukudi district, the accuracy of rainfall ranged from 64 to 78 per cent and it was 78 per cent for day 1 and 77 per cent for day 3 . However the district registered only 70 percent score value when compared to other two districts.

\section{Critical Success Index or Threat Score (CSI)}

It is a measure of relative forecasting accuracy (e.g. rain or no rain). It varies from 0 to 1 with 1 indicating perfect forecast and it is the ratio of the number of hits (correct event forecast) to the number of events which occurred plus the number or false alarms (incorrect event forecasts). Critical Success Index or the Threat Score (CSI) was ranged from 0.45 to $0.58,0.58$ to 0.69 and 0.44 to 0.60 for Virudhunagar, Tirunelveli and Thoothukudi district, respectively with an average CSI score of $0.51,0.63$ and 0.53 . Like Forecast Accuracy (ACC), Tirunelveli district evidenced for ideal forecast than the other two districts. 
Table.1 Verification of Rainfall forecast for southern districts of Tamil Nadu (April 2015- March 2016) for Virudhunagar District

\begin{tabular}{|c|c|c|c|c|c|c|c|c|}
\hline Days & NN (D) & NY (C) & YN (B) & YY (A) & ACC & CSI & HK & HSS \\
\hline Day 1 & 48 & 7 & 17 & 33 & 0.78 & 0.58 & 0.56 & 0.54 \\
\hline Day 2 & 47 & 7 & 25 & 26 & 0.70 & 0.45 & 0.44 & 0.38 \\
\hline Day 3 & 50 & 4 & 19 & 31 & 0.78 & 0.57 & 0.61 & 0.55 \\
\hline Day 4 & 45 & 9 & 23 & 27 & 0.69 & 0.46 & 0.41 & 0.38 \\
\hline Day 5 & 45 & 6 & 25 & 29 & 0.71 & 0.48 & 0.49 & 0.42 \\
\hline Mean & $\mathbf{4 7 . 0}$ & $\mathbf{6 . 6}$ & $\mathbf{2 1 . 8}$ & $\mathbf{2 9 . 2}$ & $\mathbf{0 . 7 3}$ & $\mathbf{0 . 5 1}$ & $\mathbf{0 . 5 0}$ & $\mathbf{0 . 4 5}$ \\
\hline
\end{tabular}

Table.2 Verification of Rainfall forecast for southern districts of Tamil Nadu (April 2015- March 2016) for Tirunelveli District

\begin{tabular}{|c|c|c|c|c|c|c|c|c|}
\hline Days & NN (D) & NY (C) & YN (B) & YY (A) & ACC & CSI & HK & HSS \\
\hline Day 1 & 37 & 8 & 13 & 47 & 0.81 & 0.69 & 0.59 & 0.60 \\
\hline Day 2 & 35 & 11 & 17 & 41 & 0.73 & 0.59 & 0.46 & 0.46 \\
\hline Day 3 & 35 & 10 & 17 & 42 & 0.74 & 0.61 & 0.48 & 0.48 \\
\hline Day 4 & 36 & 6 & 17 & 45 & 0.78 & 0.66 & 0.56 & 0.56 \\
\hline Day 5 & 32 & 9 & 22 & 42 & 0.72 & 0.58 & 0.42 & 0.41 \\
\hline Mean & $\mathbf{3 5 . 0}$ & $\mathbf{8 . 8}$ & $\mathbf{1 7 . 2}$ & $\mathbf{4 3 . 4}$ & $\mathbf{0 . 8}$ & $\mathbf{0 . 6 3}$ & $\mathbf{0 . 5 0}$ & $\mathbf{0 . 5 0}$ \\
\hline
\end{tabular}


Table.3 Verification of Rainfall forecast for southern districts of Tamil Nadu (April 2015- March 2016) for Thoothukudi District

\begin{tabular}{|c|c|c|c|c|c|c|c|c|}
\hline Days & NN (D) & NY (C) & YN (B) & YY (A) & ACC & CSI & HK & HSS \\
\hline Day 1 & 45 & 7 & 17 & 36 & 0.78 & 0.60 & 0.56 & 0.54 \\
\hline Day 2 & 47 & 4 & 23 & 31 & 0.75 & 0.53 & 0.56 & 0.49 \\
\hline Day 3 & 45 & 6 & 18 & 35 & 0.77 & 0.59 & 0.57 & 0.54 \\
\hline Day 4 & 38 & 9 & 28 & 29 & 0.64 & 0.44 & 0.34 & 0.31 \\
\hline Day 5 & 47 & 9 & 19 & 30 & 0.75 & 0.52 & 0.48 & 0.46 \\
\hline Mean & $\mathbf{4 4 . 4}$ & $\mathbf{7 . 0}$ & $\mathbf{2 1 . 0}$ & $\mathbf{3 2 . 2}$ & $\mathbf{0 . 7}$ & $\mathbf{0 . 5 3}$ & $\mathbf{0 . 5 0}$ & $\mathbf{0 . 5 0}$ \\
\hline
\end{tabular}

Fig.1 Verification of Rainfall forecast and Ratio score for southern districts of Tamil Nadu (April 2015- March 2016)

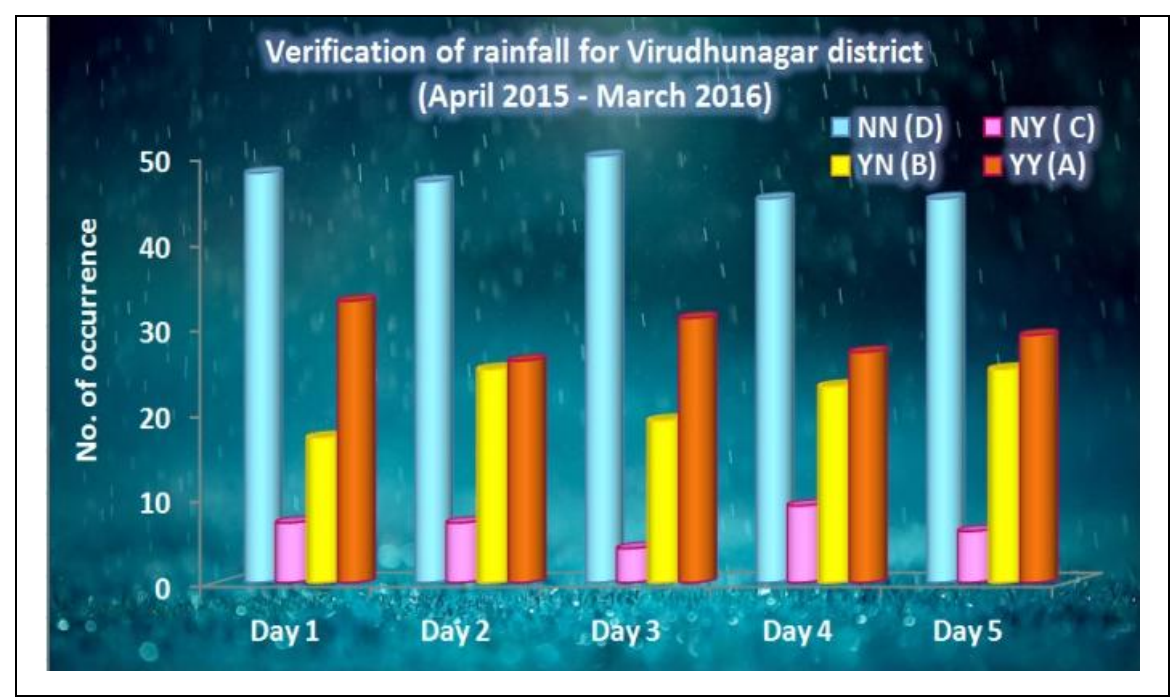



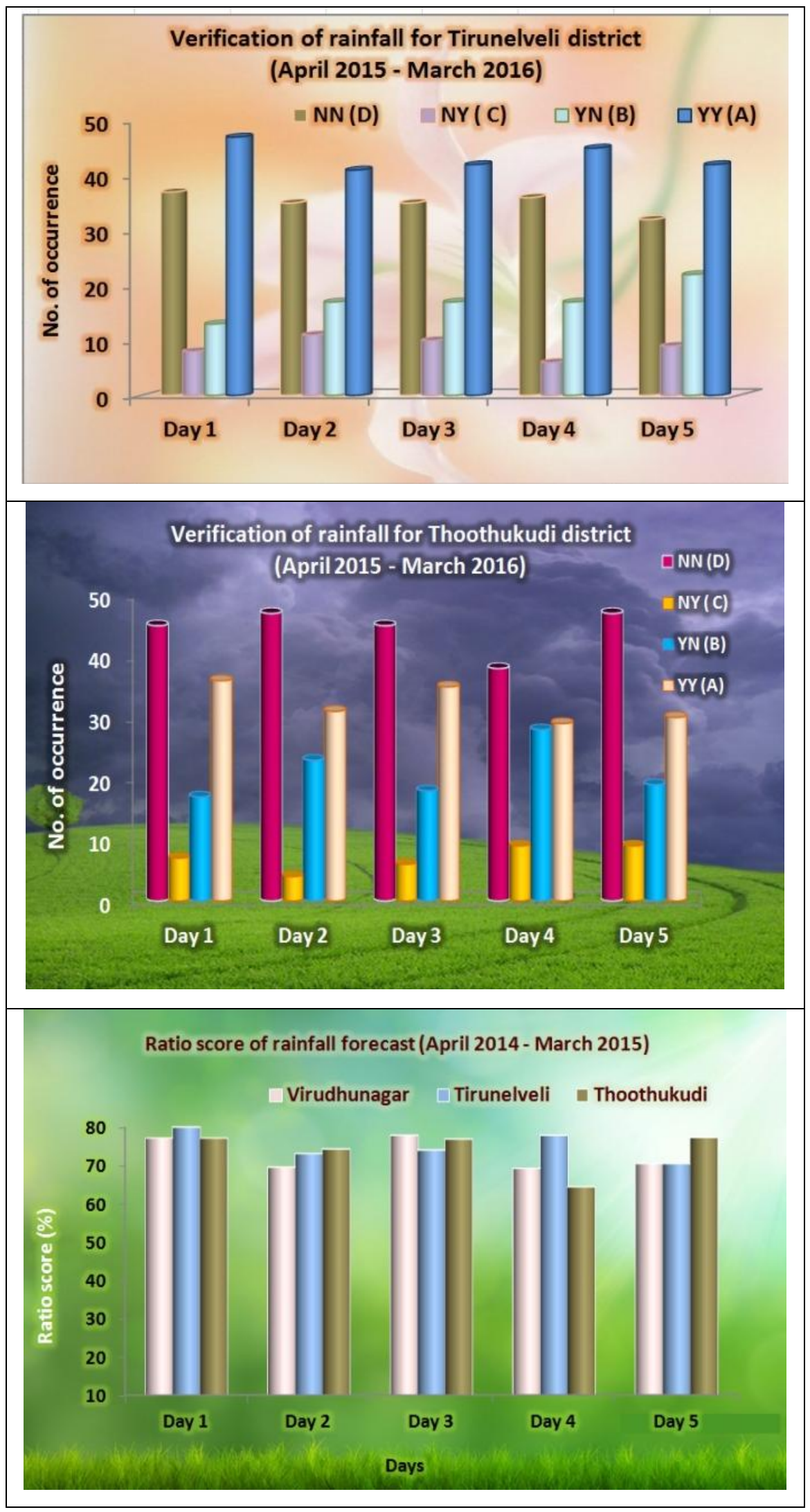
Hanssen and Kuipers Scores or True Skill Score (HK Score)

It is defined as the ratio of economic saving over climatology due to the forecast to that of a set of perfect forecasts, it ranges between -1 to +1 with 0 indicating no skill. The HK score of 0.50 was recorded for all the three districts which denote the forecast for rainfall is almost perfect during the year 2015-16.

\section{Heidke Skill Score (HSS)}

It accounts for all correct forecast (events and non- events) that would be made due to chance. It varies from -1 to +1 with 0 indicating no skill compared with random or chance forecast. The average HSS score value represented to the trend of HK score. The highest correctness of rainfall forecast was observed for day 1 and day 3 (0.54 and 0.55) followed by day $5(0.42)$ for Virudhunagar district. Similarly for Tirunelveli district, the correctness of rainfall forecast recorded on day 1 with a accuracy of 0.60 followed by day 4 (0.56). Likewise, Thoothukudi district, accounted 0.54 for day 1 and day 3 followed by 0.49 for day 2 .

In conclusion the results show that the prediction model for rainfall has been found to be quite accurate based on the various tools used in this study. The higher accuracy of rainfall prediction was noticed for day 1 and day 3 for Virudhunagar, Tirunelveli and Thoothukudi district than the other days.

\section{References}

Ferro Christopher, A.T. 2007. Verification for deterministic forecasts of rare, binary events. Walker Institute, Department of Meteorology, University of Reading.

Murphy, A.H. and Winkler, R.L. 1987. A general framework for forecast verification. Mon. Wea. Rev., 115: 1330-1338.

Murphy, A.H., Brown, B.G. and Chen, Y.S. 1989. Diagnostic verification of temperature forecast. Wea. and Forecasting, 4: 485-501.

Schafer, J.T. 1990. The critical success index as an indicator of warning skill. Wea. and Forecasting, 5: 570-575.

\section{How to cite this article:}

Joseph, M., E. Murugan and Hemalatha, M. 2017. Forecast Verification Analysis of Rainfall for Southern Districts of Tamil Nadu, India. Int.J.Curr.Microbiol.App.Sci. 6(5): 299-306. doi: http://dx.doi.org/10.20546/ijcmas.2017.605.034 